\title{
Decision Making and the Price Setting Newsvendor: Experimental Evidence
}

\author{
Ayşe Kocabıyıkoğlu and Celile Itır Gögüş \\ Faculty of Business Administration, Bilkent University, Ankara 06800, Turkey, \\ e-mail: aysekoca@bilkent.edu.tritirgogus@bilkent.edu.tr
}

M. Sinan Gönül

Department of Business Administration, Middle East Technical University, Ankara 06531,

Turkey,e-mail: msgonul@metu.edu.tr

\begin{abstract}
We present an experimental study of the price-setting newsvendor problem, which extends the traditional framework by allowing the decision maker to determine both the selling price and the order quantity of a given item. We compare behavior under this model with two benchmark conditions where subjects have a single decision to make (price or quantity). We observe that subjects deviate from the theoretical benchmarks when they are tasked with a single decision. They also exhibit anchoring behavior, where their anchor is the expected demand when quantity is the decision variable and is the initial inventory level when price is the decision variable. When decision makers set quantity and price concurrently, we observe no significant difference between the normative (i.e., expected profit-maximizing) prices and the decision makers' price choices. Quantity decisions move further from the normative benchmarks (compared to when subjects have a single decision to make) when the ratio of cost to price is less than half. When this ratio is reversed, there is no significant difference between order levels in single- and multi-task settings. In the multidecision framework, we also observe a tendency to match orders and expected demand levels, which subjects can control using prices. [Submitted: October 31, 2013. Revised: March 4, 2015. Accepted: June 10, 2015.]
\end{abstract}

\section{Subject Areas: Behavioral operations management, and Price-setting newsvendor problem.}

\section{INTRODUCTION}

Behavioral studies of models for managing inventory in the face of demand uncertainty have received significant attention in the literature in the past decade (e.g., Schweitzer \& Cachon, 2000; a detailed review of the related literature is presented below). This research stream has mainly focused on the traditional newsvendor set-up, where the order quantity is the only problem parameter under the decision

*We gratefully acknowledge financial support from Middle East Technical University - Scientific Research Grant BAP-04-02-2012-001. 
maker's control. However, pricing policies have become a fundamental component of manufacturing and service companies' operations in the past two decades, as price is one of the most effective variables that managers can use to encourage or discourage demand in the short run (Elmaghraby \& Keskinocak, 2003). Furthermore, advances in information technology have enabled firms to make and change pricing and inventory decisions simultaneously to improve profits (Chen \& Simchi-Levi, 2004).

In this article, we study decision making in a laboratory setting under the price-setting newsvendor model, which extends the traditional framework by allowing the decision maker to determine both the order quantity and the selling price. We compare behavior under this model with two benchmark conditions, where decision makers are tasked with a single decision under each condition. In the first condition, our subjects face the traditional newsvendor setting, that is, they set the order quantity of a product with uncertain demand, while the price of the item is given. The other benchmark condition allows subjects to determine the selling price (which impacts demand), while the initial stock level is determined exogenously. In both of our benchmark conditions, to obtain comparable results, the given parameter is set at its normative (i.e., expected profit-maximizing) level under the newsvendor-with-pricing problem.

To the best of our knowledge, until now, models that enable decision makers to control prices have not been studied from a behavioral perspective in the simple newsvendor setting, despite their many practical applications in manufacturing and service environments (Chan, Shen, Simchi-Levi, \& Swann, 2004). For example, in July 2005, booksellers and retailers in the United Kingdom had to make simultaneous pricing and quantity decisions while preparing for the first few days following the publication of J.K. Rowling's Harry Potter and the Half-Blood Prince so that they could gain a crucial market share in a price and availability war (Raz \& Porteus, 2006). Similarly, a recent survey finds that 52 companies that practice capacity management in Europe and North America manage price and quantity decisions concurrently (Kolisch \& Zatta, 2010). Systems that integrate operational and pricing decisions have been adopted by many companies, such as NBC (Bollapragada, Cheng, Phillips, \& Garbiras, 2002), ShopKo (Merrick, 2001), J.C. Penney, Dell Computers, FairMarket, CompUSA and Amazon (Elmaghraby \& Keskinocak, 2003; Chen \& Simchi-Levi, 2004, 2010), and are also used in setting prices for restaurant menus (Kimes, Barrash, \& Alexander, 1999; Kimes, 1999) and tickets to Broadway shows (Varian, 2005; Healy, 2014). Furthermore, there is substantial anecdotal evidence that suggests newsvendor decisions can have significant consequences in practice (Schweitzer \& Cachon, 2000). Hence, we believe it is worthwhile to investigate how decision makers determine order levels and the selling prices.

Decision patterns observed under the benchmark quantity problem in our study are consistent with the findings in the behavioral literature (e.g., Schweitzer \& Cachon, 2000); our subjects place orders between the normative quantity and the mean demand, and they order more than the normative level when the ratio of purchasing cost to selling price is greater than half, and order less than the normative quantity when the relationship between cost and price is reversed. 
When subjects determine the selling price, given an initial stock level, their decisions again deviate from normative benchmarks, but this effect is less pronounced compared to the traditional newsvendor setting. Furthermore, similar to the benchmark quantity condition, the driver behind the decision patterns observed under this model appears to be the subjects' tendency to anchor. Specifically, they anchor on the quantity to sell (which is given), and use price to adjust mean demand.

Within a more-complex inventory management setting (i.e., when subjects are asked to determine price and quantity concurrently), pricing decisions move closer to normative benchmarks. In fact, we observe no significant differences between subjects' average price decisions and the theoretical levels. Quantity decisions under this setting move further from the normative levels compared to decisions under the traditional newsvendor problem. However, it should be noted that the difference between average quantity decisions under the newsvendor-withpricing model and the single-task framework is not significant when the ratio of cost to price is greater than half. We also observe that when subjects can control both price and order quantity, they tend to choose price levels that lead to mean demands that match their order decisions.

\section{Related Literature}

This article is related to several streams of literature that consider operations models from a behavioral perspective, including experimental studies of how decision makers set order quantity and price levels, as well as behavioral contracting. For an overview of the behavioral operations management literature, the reader is referred to Bendoly, Donohue, and Schultz (2006), Gino and Pisano (2008), Loch and $\mathrm{Wu}$ (2008), and Bendoly, Croson, Goncalves, and Schultz (2010).

The traditional newsvendor problem, which allows the decision maker to control the order quantity, has received significant attention in the behavioral literature in the past decade. Schweitzer and Cachon (2000) hold the seminal work in this field, and establish the pull-to-center effect, that is, the tendency of subjects to anchor on the mean demand and adjust towards the normative order. The pull-to-center effect has been confirmed by Benzion, Cohen, Peled, and Shavit (2008), Bolton and Katok (2008), Bostian, Holt, and Smith (2008), and Lurie and Swaminathan (2009). Other experimental works on the newsvendor problem have extended Schweitzer and Cachon's (2000) setting to study framing (Schlutz, McClain, Robinson \& Thomas, 2007), group decision making (Gavirneni \& Xia, 2009), the impact of information (Gavirneni \& Isen, 2010), the relationship between cognitive reflection and newsvendor decisions (Moritz, Hill, \& Donohue, 2013), random errors in ordering (Kremer, Minner, \& Van Wassenhove, 2010) and overconfidence (Ren \& Croson, 2013). Although most laboratory analysis of the newsvendor problem has been done with students as subjects, Bolton, Ockenfels, and Thonemann (2012) show that experienced managers' behavior is very similar.

Katok and $\mathrm{Wu}$ (2009) study ordering behavior under different supply chain contracts; in particular, they consider buyback and revenue-sharing contracts and find evidence of anchoring and minimizing ex post inventory error. Wu and Chen 
(2014) extend Katok and Wu's (2009) setting to other types of contracts, including wholesale price, all-unit discount, incremental discount and sales target rebate.

Studies that examine how managers set prices in an experimental setting include Ho and Zhang (2008), who investigate the use of fixed fees by manufacturers in nonlinear pricing contracts and propose loss aversion as the key explanation of the behavioral patterns observed. Kalkanci, Chen, and Erhun (2011) compare price-only contracts with more complex all-unit quantity discount contracts under asymmetric demand information, and show simple channels provide much better coordination. In yet another study, Lim and Ho (2007) investigate the number of optimal marginal prices in a price contract and show that increasing the number of marginal prices up to three increases channel efficiency.

\section{Structure}

The rest of the article is organized as follows: The next section presents the details of our experimental design and implementation, Section 3 reports our results and Section 4 summarizes our findings and provides some concluding remarks.

\section{EXPERIMENTAL DESIGN}

There were three conditions in our experimental studies: $Q, P$, and $P Q$. Under all conditions, subjects made newsvendor decisions over several experimental rounds. The factor that distinguished these conditions was the type of decision(s) the subjects were required to make. In the $P Q$ condition, subjects were asked to decide how much of a given item to order $(q)$ and the selling price of the item $(p)$, while in the other two conditions, they were asked to set either the quantity (condition $Q$ ) or the price (condition $P$ ).

The subjects made price and/or quantity decisions over 30 experimental rounds. We varied the cost of each unit purchased $(c)$ after 15 rounds under all conditions. Specifically, we used $c=8$ under the high-margin treatment and $c=30$ under the low-margin treatment. To check for order effects, some subjects faced the low-margin treatment first (in Rounds 1-15) and the high-margin treatment second (in Rounds 16-30), while the order was reversed for the rest of the subjects (order effects refer to the possibility that subjects' experiences in an experiment might bias their decisions in subsequent experiments (Camerer, 2003)).

In the $P Q$ condition, the demand for the item, $D(p)$, was price dependent and uncertain. In the price-setting newsvendor literature, various functional forms are used to capture the dependency of demand on price (e.g., Petruzzi \& Dada, 1999). In our experiments, we used the additive-linear model, $D(p)=a-b p+Z$, where $a$, $b>0$ are constants, and $Z$ is a price-independent random variable. The deterministic portion $(a-b p)$ captures the price dependency, and implies demand decreases in price, an assumption that is valid "for almost all items, almost all of the time" (Phillips, 2005). The random portion of demand, $Z$, can be thought of as a sales driver that is uncertain, or not perfectly controlled by the decision maker. Examples include market size, personal disposable income, product quality or a reference price (e.g., Hanssens, Parsons \& Schultz, 2001). In our experiments, we set the demand parameters at $a=250, b=5$ and $Z \sim \operatorname{Uniform}(0,50)$. The distribution of $Z$ 
and values of $a$ and $b$ remained constant throughout the experimental rounds. The realizations of $Z$ in each round were determined randomly prior to the experiment and were the same for each subject.

Unlike the traditional newsvendor model, where there is only one decision variable (i.e., order quantity), the price-setting newsvendor problem does not have a closed form solution. The normative quantity and price pair, $q^{*}$ and $p^{*}$, can be found by first solving the profit function $\Pi(p, q)=p \mathrm{E}[\min (D(p), q)]-c q$ for the normative order quantity $q^{*}(p)$ (using the well-known critical fractile condition $\mathrm{P}\left(D(p) \geq q^{*}(p)\right)=c / p$; e.g. Porteus, 2002), and then substituting this expression in the profit function $\Pi$ to obtain a univariate function $\Pi\left(p, q^{*}(p)\right)$, which can be solved for $p$. Alternatively, the opposite sequence, solving the profit function $\Pi(p$, $q$ ) for $p^{*}(q)$ first, and then maximizing the univariate function $\Pi\left(p^{*}(q), q\right)$ over $q$, yields the same result (Kocabiyikoglu \& Popescu, 2011). The normative price and quantity decisions, based on the methodology described above and corresponding to the cost levels and demand parameters in our experiments, were $q^{*}=132$ and $p^{*}=31$ under the high-margin treatment and $q^{*}=58$ and $p^{*}=41$ under the low-margin treatment. Note that these values correspond to cost-to-price ratios of $c / p=8 / 31=0.25<0.5$ under the high-margin treatment and $c / p=30 / 41=$ $0.73>0.5$ under the low-margin treatment. Also note that under the low-margin treatment, having too many units relative to demand (overage) is more detrimental to profits (because of the higher cost), and under the high-margin treatment, having too few units relative to demand (underage) hurts profits more (because the unit margin $p-c$ is higher).

Our other experimental conditions, $P$ and $Q$, were benchmark conditions, where the subjects were tasked with a single decision. In particular, under the $Q$ condition, subjects were given cost, demand and price information at the beginning of each experimental round, and were asked to determine the order quantity. In other words, they faced the traditional newsvendor setting, which treats price as given. The prices in this condition were set at their normative levels in the price-setting newsvendor problem $\left(p^{*}=31\right.$ under the high-margin treatment and $p^{*}=41$ under the low-margin treatment). We used the normative prices to be able to compare subjects' quantity decisions under conditions $Q$ and $P Q$. Under $Q$, since price was given, demand was described to the subjects as consisting of a sure "base" demand and a random component. The base demand was given as $a-b p^{*}=250-5(31)=95$ under the high-margin treatment and $a-b p^{*}=250-5(41)$ $=45$ under the low-margin treatment, while the random portion was distributed $\operatorname{Uniform}(0,50)$.

Our last condition, $P$, was analogous to $Q$. Under this condition, subjects were given the normative quantity levels under the newsvendor-with-pricing problem (again, for comparability purposes), as well as cost and demand information, and were asked to set the selling price. In particular, they were told that they had 132 units to sell under the high-margin treatment, and under the low-margin treatment the corresponding initial stock level was 58. Demand was price dependent and the same as demand under $P Q$, that is, $D(p)=250-5 p+Z$, with $Z \sim \operatorname{Uniform}(0,50)$.

A total of 189 subjects participated in the experiments. All were undergraduate students and had taken at least one introductory Operations Management or 
Table 1: Summary of experimental conditions.

\begin{tabular}{|c|c|c|c|c|}
\hline Condition & Decision & Treatment & Information given & $\begin{array}{c}\text { Number of } \\
\text { subjects }\end{array}$ \\
\hline$P Q$ & Price \& quantity & $\begin{array}{l}\text { High margin } \\
\text { Low margin }\end{array}$ & $\begin{array}{l}D(p)=250-5 p+Z, \\
\quad Z \sim \text { Uniform }(0,50), \text { cost }=8 \\
D(p)=250-5 p+Z, \\
\quad Z \sim \text { Uniform }(0,50), \text { cost }= \\
30\end{array}$ & 61 \\
\hline$Q$ & Quantity & $\begin{array}{l}\text { High margin } \\
\text { Low margin }\end{array}$ & $\begin{array}{l}D=95+Z, \\
Z \sim \text { Uniform }(0,50), \text { cost }= \\
\quad 8, \text { price }=31 \\
D=45+Z, \\
Z \sim \text { Uniform }(0,50), \text { cost }= \\
30, \text { price }=41\end{array}$ & 64 \\
\hline$P$ & Price & $\begin{array}{l}\text { High margin } \\
\text { Low margin }\end{array}$ & $\begin{array}{l}D(p)=250-5 p+Z, \\
Z \sim \text { Uniform }(0,50), \text { cost }= \\
8, \text { quantity }=132 \\
D(p)=250-5 p+Z, \\
Z \sim \text { Uniform }(0,50), \text { cost }= \\
30, \text { quantity }=58\end{array}$ & 64 \\
\hline
\end{tabular}

Quantitative Methods course. No subject participated in more than one condition. Table 1 gives a summary of our conditions and the number of subjects in each condition.

\section{Laboratory Implementation}

All experimental sessions followed the same protocol. When the subjects arrived at the experimental lab, they were given instructions that explained they were going to act as the manager of a small retail firm that buys a product from a supplier and sells it to end consumers. The instructions given to the subjects assigned conditions $P$ and $P Q$ explained that the price they charged customers would impact product demand when they offered it for sale in the market, and outlined the demand function. The instructions specified that the objective was profit maximization, and described how profit was calculated; they also included an explanation of the tradeoff between underage and overage, and illustrated these concepts with examples.

After all the subjects finished reading the instructions on their own, the experimenter read them aloud, using PowerPoint slides to illustrate concepts and examples, and answered questions. At the end of this training period, a short test was administered to the subjects to ensure they understood the instructions. Only the participants who completed the test successfully began the experimental rounds.

The experiments were conducted with specifically programmed software based on the Visual Basic for Applications (VBA) platform (Figure A13 in the Appendix provides sample screenshots of the interface). At the beginning of each round, subjects were provided with demand, cost, price (if they were assigned to 
Figure 1: Subjects' average quantity decisions.

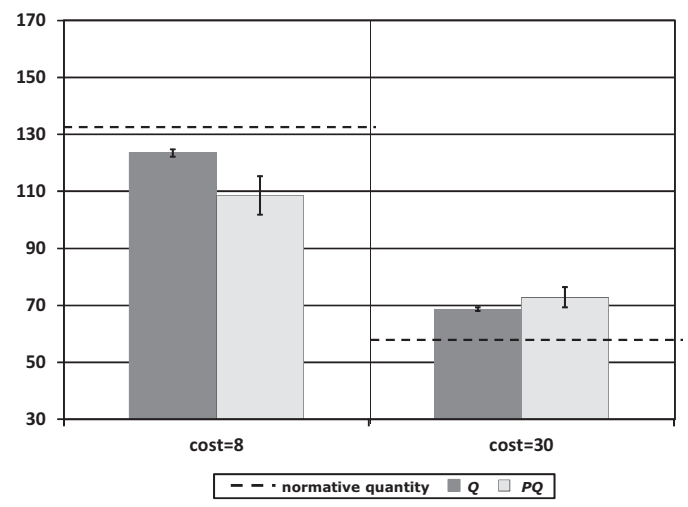

condition $Q$ ) and quantity (if they were assigned to condition $P$ ) information. Then, they were asked to set the order quantity if they were assigned to condition $Q$, the selling price if they were assigned to condition $P$ and the price and the quantity if they were assigned to condition $P Q$.

After making their decision(s), subjects learned the actual demand for that round (which was a function of their price decision if they were assigned to $P Q$ or $P$ ) and their realized revenue, cost and profit, as well as the number of unsold units and the number of customers turned away.

The initial five rounds were dubbed the "pilot rounds," and used to familiarize the subjects with the interface and the task. Hence, data from this part of the experiment was not used in any of the subsequent analyses. Subjects were not informed of the total number of rounds prior to the experiment, and they were debriefed and dismissed after they completed the 5 pilot rounds and the 30 experimental rounds. An information message was displayed on the screen after the fifteenth experimental round, when there was a change in the problem parameters. None of the subjects received information about other subjects' performances and subjects were not allowed to communicate during the experiment. Each session lasted approximately 90 minutes, including the training period and pilot rounds.

\section{RESULTS}

We first provide descriptive statistics for the decisions under conditions $Q, P$, and $P Q$, followed by separate behavior analyses for each model. We conclude with a comparison of our subjects' quantity and price decisions and the corresponding performances (in terms of profits achieved) for the models we examine in this article.

Figures 1 and 2 provide a visual summary of our subjects' average decisions, while Figures 3-6 give the average decision per experimental round for all 
Figure 2: Subjects' average price decisions.

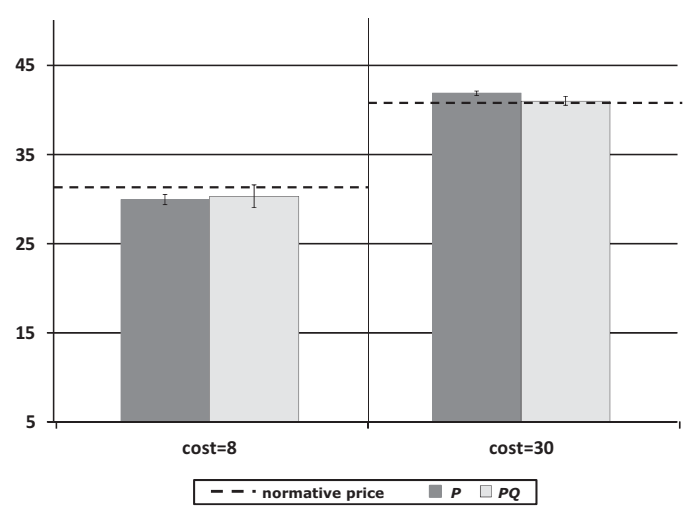

Figure 3: Subjects' average quantity decisions per round: $Q$ and $P Q$ high-margin treatment.

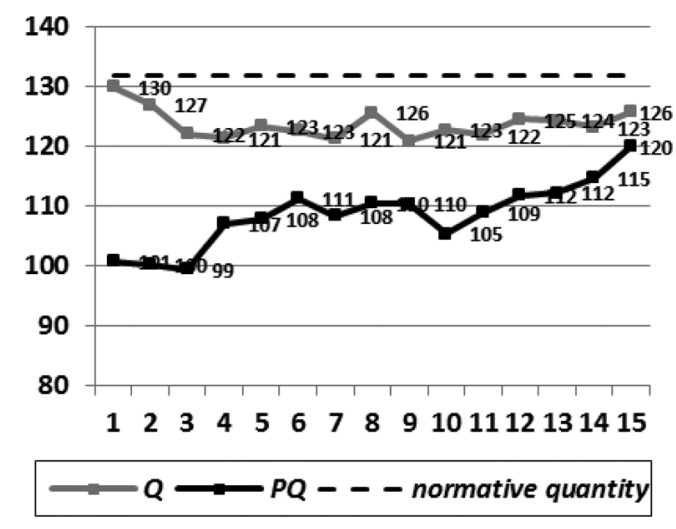

experimental conditions and cost treatments considered (histograms of our subjects' decisions are provided in Figures A1-A 8 in the Appendix). Tables 2 and 3 give descriptive statistics for our subjects' quantity and price decisions, respectively, including average decision, standard deviation, median and normative decisions, as well as an overview of the p-values and W-statistics for the comparisons of average decisions with normative benchmarks that are presented in the following sections. Additional descriptive statistics on the overall and average decisions are given in Tables A1 and A2 in the Appendix.

For the majority of our analyses, we used the Wilcoxon test (Siegel, 1956) for the comparisons. The unit of analysis is the mean demand decision for each of the 15-round intervals (i.e., the same cost treatment) for each subject. We checked our data for any order effects- that is, whether the order of cost treatments impacted our subjects' decisions_-and found none. 
Figure 4: Subjects' average quantity decisions per round: $Q$ and $P Q$ low-margin treatment.

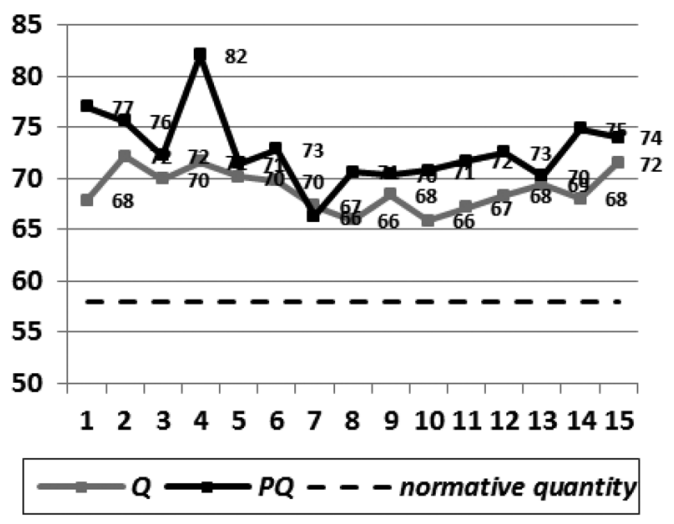

Figure 5: Subjects' average price decisions per round: $P$ and $P Q$ high-margin treatment.

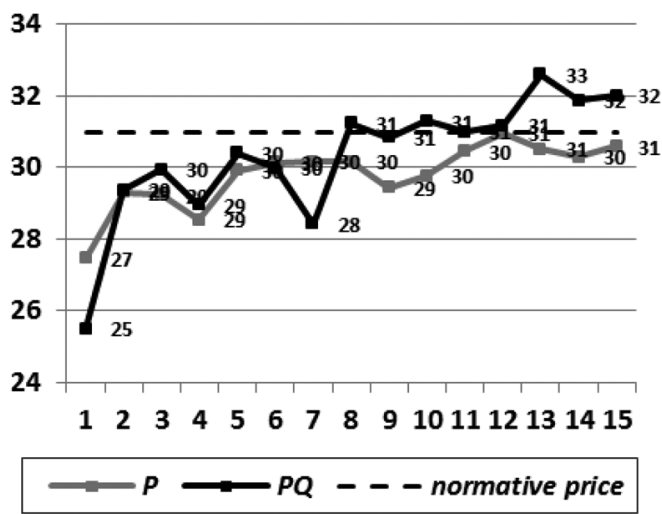

Table 2: Descriptive statistics and Wilcoxon tests: quantity decisions.

\begin{tabular}{|c|c|c|c|c|c|c|c|}
\hline & $\begin{array}{l}\text { Average } \\
\text { quantity }\end{array}$ & $\begin{array}{l}\text { Median } \\
\text { quantity }\end{array}$ & $\begin{array}{l}\text { Standard } \\
\text { deviation }\end{array}$ & $\begin{array}{c}\text { Normative } \\
\text { quantity }\end{array}$ & $p$-value & W-statistic & $\begin{array}{c}\text { Sample } \\
\text { size }\end{array}$ \\
\hline \multicolumn{8}{|c|}{ High margin } \\
\hline$Q$ & 123.45 & 121.5 & 10.32 & & $p<.0001$ & 118 & 64 \\
\hline$P Q$ & 108.57 & 90.87 & 52.7 & 132 & $p=.001$ & 476 & 61 \\
\hline \multicolumn{8}{|c|}{ Low margin } \\
\hline$Q$ & 68.70 & 69.1 & 5.06 & & $p<.0001$ & 2074 & 64 \\
\hline$P Q$ & 72.86 & 72.2 & 27.75 & 58 & $p<.0001$ & 1491.5 & 61 \\
\hline
\end{tabular}


Figure 6: Subjects' average price decisions per round: $P$ and $P Q$ low-margin treatment.

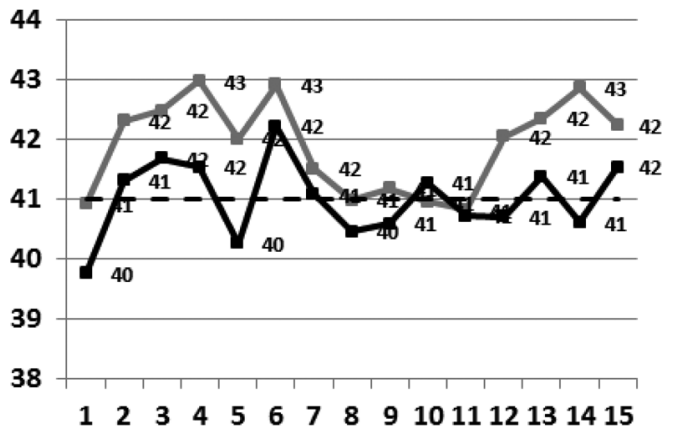

$\longrightarrow P \longrightarrow P Q---$ normative price

Table 3: Descriptive statistics \& Wilcoxon tests: price decisions.

\begin{tabular}{cccccccc}
\hline \multicolumn{2}{c}{$\begin{array}{c}\text { Average } \\
\text { price }\end{array}$} & $\begin{array}{c}\text { Median } \\
\text { price }\end{array}$ & $\begin{array}{c}\text { Standard } \\
\text { deviation }\end{array}$ & $\begin{array}{c}\text { Normative } \\
\text { price }\end{array}$ & \multicolumn{1}{c}{$p$-value } & W-statistic & $\begin{array}{c}\text { Sample } \\
\text { size }\end{array}$ \\
\hline \multicolumn{2}{l}{ High margin } \\
$P$
\end{tabular}

\section{Study $Q$}

Previous literature on behavioral studies of the traditional newsvendor model establishes two robust behavioral patterns: the pull-to-center effect, which refers to the tendency of decision makers to anchor order decisions on the mean demand, and the too-low/too-high pattern, which suggests that decision makers order less than the normative quantity under the high-margin treatment, and more under the low-margin treatment. Next, we investigate whether these behavioral patterns exist in our data.

We first provide a comparison of our subjects' decisions with the normative benchmarks given in Table $2\left(q^{*}=58\right.$, and $q^{*}=132$, under the low- and highmargin treatments, respectively). On average, our subjects ordered amounts that were significantly lower than the normative quantity under the high-margin treatment, and quantities that were significantly higher than the normative benchmark under the low-margin treatment ( $p<.0001$ for both comparisons).

We also compared our subjects' average quantity decisions under condition $Q$ with the corresponding expected demand levels. Note from Table 1 that in condition $Q$, mean demand is equal to $\mathrm{E}\left[D\left(p^{*}\right)\right]=250-5 p^{*}+\mathrm{E}[Z]=275-5 p^{*}$ (as $\mathrm{E}[Z]=25$ for $Z \sim$ Uniform $(0,50)$ ). This result yields a mean demand of 120 under 
the high-margin treatment and 70 under the low-margin treatment (because the normative price is $p^{*}=31$ when $c=8$, and $p^{*}=41$ when $c=30$ ). Wilcoxon tests revealed that, on average, our subjects ordered quantities significantly higher than the mean demand when $c=8(123.45$ vs. $120 ; p=.002)$ and significantly lower quantities than $\mathrm{E}\left[D\left(p^{*}\right)\right]=70$ under the low-margin treatment $(p=.018)$. At the individual level, $47.5 \%$ of all decisions fell between the normative quantity and the mean demand [120,132] under the high-margin treatment (456 of 960 decisions); the corresponding figure was $40.31 \%$ for the range [58,70] under the low-margin treatment. The results outlined above lead us to conclude that our subjects' ordering behavior under condition $Q$ was consistent with the findings in the behavioral literature regarding the traditional newsvendor problem.

\section{Study $P$}

This section considers decisions under condition $P$, where our subjects were given an initial order quantity and asked to determine the selling price.

We first compared the average prices set by our subjects in this condition with the corresponding normative price benchmarks given in Table 3 ( $p^{*}=31$ and $p^{*}=41$ under the high- and low-margin treatments, respectively). We observed that our subjects, on average, set prices significantly lower than the normative benchmark under the high-margin treatment $(p=.004)$ and set prices significantly higher than the normative benchmark under the low-margin treatment $(p<.0001)$.

Next, we study the drivers behind the behavioral patterns observed under this condition. As outlined in the previous section, when determining the quantity, given the selling price and the mean demand, our subjects exhibited a strong tendency to anchor their decisions on the mean and adjust towards the normative quantity. To investigate whether a similar anchoring behavior occurred when our subjects were given the initial order quantity and asked to set the price (which was one of the determinants of demand), we calculated the expected demand levels corresponding to their pricing decisions in each experimental round. Specifically, for a price decision $p$, in a given round, expected demand level is equal to $\mathrm{E}[D(p)]=250$ $5 p+\mathrm{E}[Z]=275-5 p$ (because $\mathrm{E}[Z]=25$ for $Z \sim$ Uniform $(0,50)$ ). We observed that the average of expected demands corresponding to our subjects' price decisions was 125.30 under the high-margin treatment; this figure was significantly lower than the order quantity $132(p=.004)$. Under the low-margin treatment, the corresponding figure was significantly higher than the initial stock level (65.64 vs. 58; $p<.0001$ ). Figures 7 and 8 provide a visual summary of the expected demand levels corresponding to our subjects' price decisions across the experimental rounds.

At the individual level, $59.69 \%$ of all price decisions led to mean demands below the initial inventory of 132 in the high-margin treatment; in the low-margin treatment, $65.10 \%$ of the mean demands generated by our subjects through their pricing decisions were above the quantity 58 (histograms of the expected demand levels corresponding to our subjects' price decisions under condition $P$ are given in Figures A9 and A10 in the Appendix). At the subject level, 42 of the 64 subjects who participated in this condition set prices that led to average expected demand levels below the quantity 132 in the high-margin treatment. In the low-margin 
Figure 7: Mean demands corresponding to subjects' price decisions per experimental round: $P$ high-margin treatment.

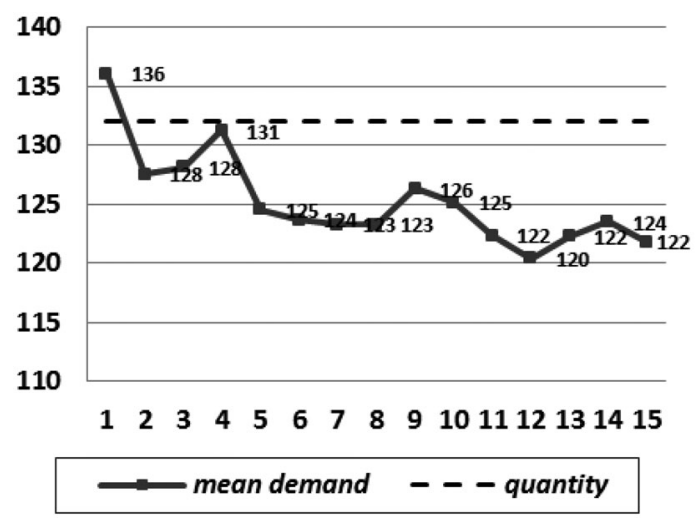

Figure 8: Mean demands corresponding to subjects' price decisions per experimental round: $P$ low-margin treatment.

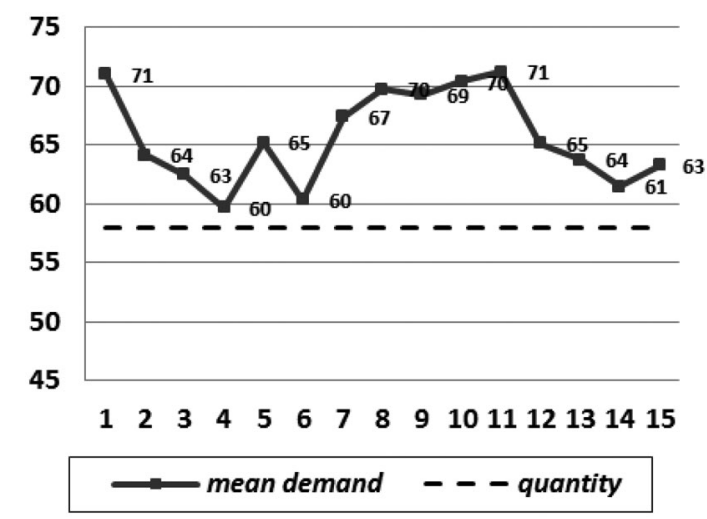

treatment, 51 of 64 subjects' price decisions generated mean demands above the initial quantity level 58.

Our analysis in this section suggests that when determining price, subjects exhibit a tendency to anchor on the quantity level, and use price as a lever to adjust expected demand. This adjustment is downwards under the high-margin treatment, where having too few units relative to demand (underage) is more detrimental to profits, whereas it is upwards under the low-margin treatment, where having too many units relative to demand (overage) hurts profits more. 
Table 4: Descriptive statistics: difference between quantity decisions and mean demands corresponding to price decisions under $P Q$.

\begin{tabular}{lcccc}
\hline & Average & Median & Min & Max \\
\hline High margin & 34.5 & 20 & 0 & 212 \\
Low margin & 23.84 & 15 & 0 & 250 \\
\hline
\end{tabular}

\section{Study $\boldsymbol{P Q}$}

Figure 1 suggests that under condition $P Q$, the pattern of our subjects' ordering behavior with respect to the normative quantity is similar to that observed in condition $Q$. Specifically, on average, our subjects ordered significantly lower quantities than the normative benchmark under the high-margin treatment (108.57 vs. $\left.q^{*}=132 ; p=.001\right)$, and significantly higher quantities than the normative benchmark under the low-margin treatment $\left(72.86\right.$ vs. $\left.q^{*}=58 ; p<.0001\right)$. On the other hand, Wilcoxon tests comparing actual and normative prices found no significant differences between the subjects' average price decisions in condition $P Q$ and the theoretical benchmarks (30.31 vs. $p^{*}=31$ under the high- margin treatment, $p=.648 ; 41.01$ vs. $p^{*}=41$ under the low-margin treatment, $p=.934$ ).

As outlined in the previous sections, the driver behind the behavioral patterns observed when subjects were tasked with a single decision was a tendency to anchor. This anchor was the mean demand when they set the order quantity, and it was the initial stock when they set the price. Under the condition $P Q$, price and order quantity were both decision variables, so we compared our subjects' order quantities with the expected demands corresponding to their price decisions. Specifically, we focused on the absolute difference between quantity and expected demand to investigate whether our subjects followed a matching strategy, where they tried to set prices that yielded mean demand levels close to their order decisions. For this analysis, for a given price and quantity decision pair $(p, q)$ in an experimental round, we calculated $|\mathrm{E}[D(p)]-q|$, where $\mathrm{E}[D(p)]=250-5 p+\mathrm{E}[Z]$. Table 4 summarizes the corresponding descriptive statistics.

Figures 9 and 10 provide a visual summary of the expected demands generated by our subjects' price decisions and order levels across experimental rounds. From Figure 10, we see that under the low-margin treatment, the average order quantities and mean demand levels corresponding to our subjects' price decisions remained quite close throughout the experimental rounds; the highest difference was observed in Round 4 (14.83), while the lowest difference was observed in Round 11 (0.32). Under the high-margin treatment, we see from Figure 9 that our subjects' order decisions and the mean demand levels they generated through their price decisions were quite different in the initial rounds (the highest difference, 46.88 , was observed in the first round), but got closer over the course of repeated plays (the difference between these two values was at its lowest, 0.18, in Round 13).

At the subject level, the difference between average order quantities and expected demand levels corresponding to price decisions ranged between 0 and 
Figure 9: Average quantity decisions vs. mean demands corresponding to subjects' price decisions per experimental round: $P Q$ high-margin treatment.

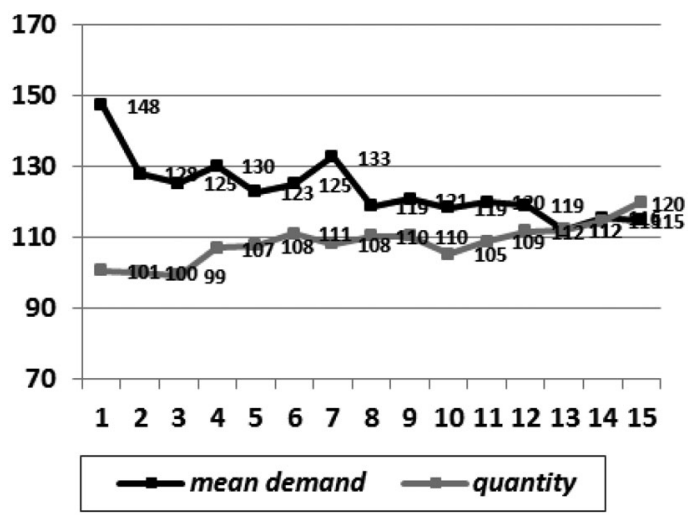

Figure 10: Average quantity decisions vs. mean demands corresponding to subjects' price decisions per experimental round: $P Q$ low-margin treatment.

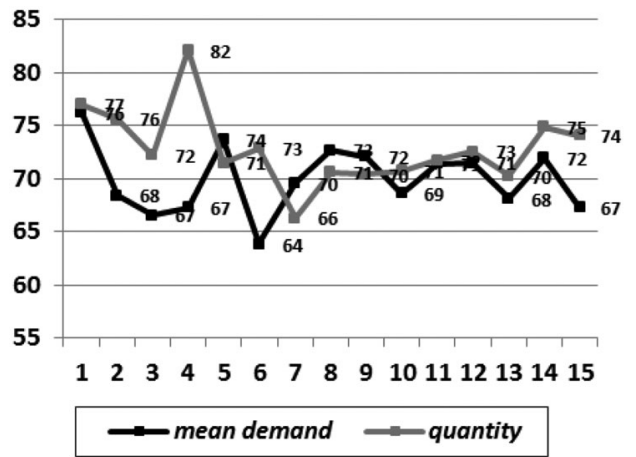

135.93 under the high-margin treatment and between 1 and 92.53 under the lowmargin treatment. Approximately half of our subjects chose price levels that led to an average difference less than 20 between mean demand and quantity under the low-margin treatment (29 out of 61 subjects); under the high-margin treatment, 31 of 61 subjects generated differences less than 25 . In particular, we had one subject who followed a pure matching strategy under the high-margin treatment; the difference between his order decisions and the expected demand levels corresponding to his price decisions was zero across all 15 experimental rounds.

At the individual level, in 81 out of 915 decisions under the high-margin treatment, and 114 out of 915 decisions under the low-margin treatment, the mean demand level corresponding to our subjects' price decisions and their order quantities were equal to each other. Furthermore, the difference between the expected demand and the order decision was less than 25 in $55.73 \%$ of decisions under the 
high-margin treatment; the corresponding figure was $65.9 \%$ under the low-margin treatment (histograms of the difference between the mean demands corresponding to our subjects' price decisions and their order quantities are given in Figures A11 and A12 in the Appendix).

Based on the analysis provided above, we conclude that while making price and quantity decisions concurrently, our subjects showed a tendency to try to match order quantity and expected demand (which they could influence through their pricing decisions).

\section{Comparison of decisions and performance under $Q, P$, and $P Q$}

We conclude this section with a comparison of our subjects' decisions under the three models studied in this article $(Q, P$ and $P Q)$ and their performances in terms of profits.

\section{Decision comparisons}

When we compared our subjects' quantity decisions, we observed that in the high-margin treatment, the average order decision was significantly higher under the $Q$ condition compared to the $P Q$ condition $(123.45$ vs. $108.57 ; p=.021)$. This result suggests that under this cost treatment, when subjects determined both price and quantity, their orders deviated further from the normative benchmark $\left(q^{*}=132\right)$, compared to when they set only quantity. Under the low-margin treatment, although our subjects' average quantity decision was slightly higher under condition $P Q$ compared to condition $Q$ (72.86 vs. 68.70), this difference was not significant $(p=.065)$.

When we compared our subjects' average price decisions in conditions $P$ and $P Q$ under the corresponding treatments, we observed no significant differences ( $p=.642$ under the high-margin treatment and $p=.103$ under the low-margin treatment). Also note that our subjects' average price decisions under both conditions were lower than the normative benchmark under the high-margin treatment, whereas they were higher compared to the normative price under the low-margin treatment, but these differences were not significant under condition $P Q$, as discussed in the previous subsection.

One of the referees suggested that the subjects may be rounding their price decisions to the nearest 5 . When we checked our data, we observed no evidence of rounding when the subjects were determining only the price. For example, subjects set the price as 29 and 30 almost the same number of times under the high-margin treatment (30 was the chosen price in 114 out of 960 decisions, and 29 in 113 out of 960 decisions), while prices multiples of 5 or 10 (e.g., 10, 15, 20, . . ) made up $0.5-3.5 \%$ of individual decisions. A similar pattern was observed for the low-margin treatment under this condition. Under the $P Q$ condition, we observed some evidence of rounding. In particular, under the high-margin treatment, our subjects set the price as 25,30 , and 35 in approximately $23 \%$ of all decisions (the price was 25 in 67 out of 915 decisions, 30 in 88 out of 915 decisions, and 35 in 47 out of 915 decisions); under the low-margin treatment, price levels of 40 and 45 were observed the most frequently, in $24.2 \%$, respectively $12.6 \%$, of all decisions. 
Figure 11: Profit analysis: $Q$ and $P Q$.

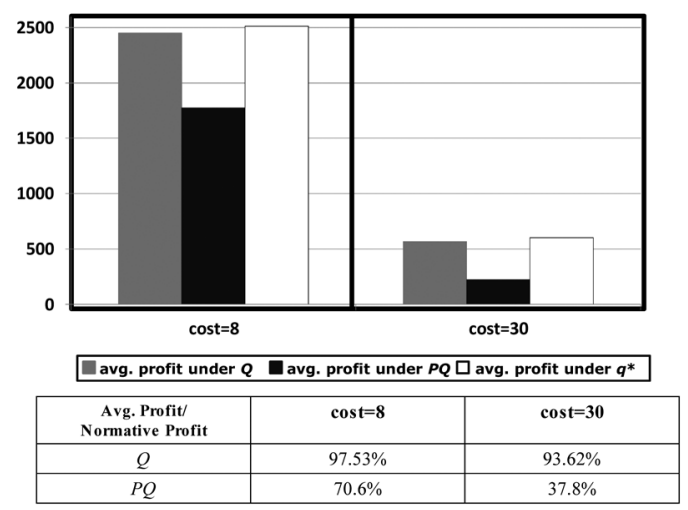

\section{Performance comparisons}

Next, we present a comparison of our subjects' performances in terms of profits under conditions $Q, P$ and $P Q$. Figure 11 plots the average profits our subjects earned in condition $Q$, the average profits they would have earned in condition $P Q$ with their quantity decisions if the selling price was set at the normative level (this approach was used to isolate the effect of quantity decisions on profits under $P Q$ and to obtain figures comparable to those in condition $Q$ ) and the average profits they could have earned if they had set the normative price and quantity at each round. This figure also provides a comparison of the proportion of actual average profit earned under both conditions to average profit under the normative order quantity. For example, on average, our subjects made a profit of 2,451 under the $Q$ condition in the high-margin treatment, whereas if they had ordered the normative quantity $\left(q^{*}=132\right)$ at each round, they would have earned 2,513; in other words, they captured $2,451 / 2,513=97.53 \%$ of the maximum profits that could have been achieved. Figure 12 provides a similar analysis for the average profits earned under $P$ and $P Q$ (further descriptive statistics about our subjects' profits, including the actual average profits in condition $P Q$, are provided in Tables A3 and A4 in the Appendix).

Under both treatments, the proportion of actual average profit earned to average profit under the normative decisions was higher when subjects were tasked with a single decision (price or quantity) compared with when they had multiple decisions to make. However, it should be noted that the lower performance levels in $P Q$ compared to $Q$ or $P$ are due both to the deviations from the normative benchmarks and to the increased variability of ordering decisions under the $P Q$ condition (see Tables 2 and 3 and Figures A1-A8 in the Appendix, which provide histograms of our subjects' decisions under $Q, P$ and $P Q$ ), because when average profits are considered, "ordering 75 every period is a more efficient strategy than alternating between orders of 50 and 100" (Bolton, Ockenfels, \& Thonemann, 2012). 
Figure 12: Profit analysis: $P$ and $P Q$.

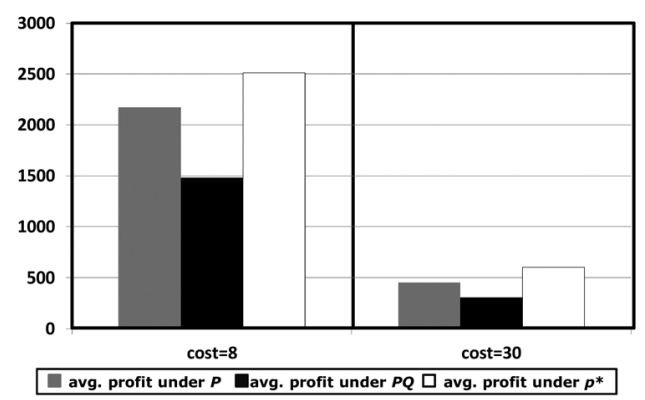

\begin{tabular}{|c|c|c|}
\hline $\begin{array}{c}\text { Avg. Profit/ } \\
\text { Normative Profit }\end{array}$ & cost $=\mathbf{8}$ & cost $=30$ \\
\hline$P$ & $86.54 \%$ & $75.29 \%$ \\
\hline$P Q$ & $58.96 \%$ & $50.85 \%$ \\
\hline
\end{tabular}

\section{CONCLUSION}

In this article, we presented an experimental study on decision making behavior under three inventory management models: (1) the traditional newsvendor problem, where decision makers determine how many units to order of an item with uncertain demand, (2) a pricing model, where decision makers are given an initial stock level and can influence demand through their price decisions, and (3) the price-setting newsvendor problem, which allows decision makers to set the selling price and the order quantity concurrently. We compared the decision patterns under the price-setting newsvendor framework with the behavior under the two benchmark quantity and price conditions, where subjects were tasked with a single decision.

Our subjects' ordering behavior under the traditional newsvendor model with respect to normative decisions was consistent with previous studies in the behavioral operations literature (e.g., Schweitzer \& Cachon, 2000; Bolton and Katok, 2008). Quantity decisions were significantly lower than the normative benchmark when the ratio of cost to price was less than half, and higher than the normative order level when the relationship between cost and price was reversed. When price was added as a decision variable to this setting, order quantities moved further from the normative levels compared to the benchmark quantity condition. The difference between the average order quantities under the traditional and pricesetting newsvendor problems was significant when the ratio of cost to price was less than half, whereas no significant difference was observed when this ratio was reversed. Research beyond the scope of this article would be needed to explore the asymmetrical patterns observed in quantity decisions.

When the subjects were given an initial stock level and asked to set the price, their decisions were again significantly different than the normative benchmarks, but closer to the theoretical levels compared to the quantity condition. Furthermore, pricing decisions did not deteriorate when subjects set the price and quantity concurrently. In fact, there was no significant difference between our subjects' pricing 
Figure 13: Managerial insights.

\section{Managerial insights}

In a typical newsvendor setting, a manager can

- determine price and/or quantity

Controlling prices

- may benefit the company by providing stronger control over managing demand, and regulating inventory and production pressures

- may help integrate the operations and marketing functions within the company

\section{Setting price or quantity only}

- Be vigilant and cautious about the decision anchors (e.g., initial quantity level, mean demand) that may be improperly used and the consequent insufficient adjustments

Setting price and quantity concurrently

- Be vigilant and cautious about the tendency to match expected demand with the order quantity

- A harder decision task and may result in higher variance in decisions

To reap the financial \& operational benefits of integration:

- Develop training \& education programs for managers

- Improve awareness of overage and underage costs

- Improve awareness on the negative impact of frequently changing decisions on long term profits

- Explore further feedback and incentive mechanisms

Specifically tailored Decision Support Systems may help!

decisions under the price-setting newsvendor problem and the normative prices, or between their average decisions when price was the only decision variable.

We also observed evidence of anchoring under our benchmark quantity and price conditions. In particular, our subjects displayed the well-established pullto-center effect (e.g., Schweitzer \& Cachon, 2000; Bolton \& Katok, 2008) under 
the traditional newsvendor model; that is, they anchored on the mean demand and insufficiently adjusted towards the normative order quantity. Our study revealed subjects used a similar anchoring heuristic when their decision variable was price. They anchored on the initial quantity level (which was given), and used price to adjust expected demand. This adjustment was upwards when the ratio of cost to price was greater than half (i.e., when having too many units relative to demand was more detrimental to profits), whereas subjects tended to choose prices that led to expected demand levels below the initial inventory when the ratio of cost to price was less than half (i.e., when having too few units relative to demand hurt profits more). Under the price-setting newsvendor model, subjects exhibited a tendency to match expected demand (which they could control via their price decisions) and order quantity, possibly in order to minimize instances of overage and underage.

Our results indicate that when decision makers are tasked with determining either the price or the quantity, they tend to set lower quantities and prices (which lead to higher mean demands) than the expected profit-maximizing levels, when lost sales are more detrimental to profits, while the opposite behavior is observed when unsold units hurt earnings more. These behavioral patterns lead to profit losses as high as $25 \%$ (compared to normative levels). When decision makers are tasked with multiple decisions (price and quantity), these losses are magnified both due to further deviations from normative quantity levels and increased variance in decisions. As mentioned in the Introduction, price is an operational tool as well as a financial one, and helps manage demand and regulate inventory and production pressures (Elmaghraby \& Keskinocak, 2003). Clearly, companies exploring strategies to integrate inventory and marketing decisions need to develop training and education programs to make the costs associated with overage and underage more salient to decision makers, and to increase awareness about the negative impact of changing decisions frequently on long-term earnings. Moreover, decision support systems which provide information about the underage and overage costs incurred as a consequence of decisions, and highlight the frequency of the change in prices or order quantities over the selling horizon can be developed. Finally, further research is required to explore tools (such as feedback and incentive mechanisms) that would help align decision patterns with profit-maximizing levels so that firms can reap the financial and operational benefits of integration (see Figure 13).

\section{REFERENCES}

Arcelus, F. J., Kumar, S., \& Srinivasan, G. (2005). Retailer's response to alternate manufacturer's incentives under a single-period, price-dependent, stochasticdemand framework. Decision Sciences, 36(4), 599-626.

Bendoly, E., Croson, R., Goncalves, P., \& Schultz, K. L. (2010). Bodies of knowledge for research in behavioral operations. Production and Operations Management, 19(4), 434-452. 
Bendoly, E., Donohue, K., \& Schultz, K. L. (2006). Behavior in operations management: Assessing recent findings and revisiting old assumptions. Journal of Operations Management, 24, 737-752.

Benzion, U., Cohen, Y., Peled, Y., \& Shavit, T. (2008). Decision-making and the newsvendor problem: An experimental study. Journal of the Operational Research Society, 59, 1281-1287.

Bollapragada, S., Cheng, H., Phillips, M., \& Garbiras, M. (2002). NBC's optimization systems increase revenues and productivity. Interfaces, 32(1), 47-60.

Bolton, G. E., \& Katok, E. (2008). Learning-by-doing in the newsvendor problem: A laboratory investigation of the role of experience and feedback. Manufacturing and Service Operations Management, 10(3), 519-538.

Bolton, G. E., Ockenfels, A., \& Thonemann, U. W. (2012). Managers and students as newsvendors. Management Science, 58(12), 2225-2233.

Bostian, A. A., Holt, C. A., \& Smith, A. M. (2008). Newsvendor "pull-to-center" effect: Adaptive learning in a laboratory experiment. Manufacturing and Service Operations Management, 10(4), 590-608.

Camerer, C. F. (2003). Behavioral game theory: Experiments in strategic interaction. Princeton, NJ: Princeton University Press.

Chan, L. M. A., Shen, Z. J., Simchi-Levi, D., \& Swann, J. L. (2004). Coordination of pricing and inventory decisions: A survey and classification. In: D. Simchi-Levi, S. D. Wu, \& Z. J. Shen (Eds), Handbook of quantitative supply chain analysis: Modeling in the E-business era. Dordrecht, The Netherlands: Kluwer Academic Publishers, pp. 225-392.

Chen, X. M. A., \& Simchi-Levi, D. (2004). Coordinating inventory control and pricing strategies with random demand and fixed ordering cost; the infinite horizon case. Mathematics of Operations Research, 29(3), 698-723.

Chen, X. \& Simchi-Levi, D. (2010). Pricing and Inventory Management, The Handbook of Pricing Management, O. Ozer \& R. Phillips (eds), Oxford University Press.

DeVericourt, F., \& Lobo, M. S. (2009). Resource and revenue management in non-profit operations. Operations Research, 57(5), 1114-1128.

Elmaghraby, W., \& Keskinocak, P. (2003). Dynamic pricing in the presence of inventory considerations: Research overview, current practices, and future directions. Management Science, 49(10), 1287-1309.

Gavirneni, S., \& Xia, Y. (2009). Anchor selection and group dynamics in newsvendor decisions-A note. Decision Analysis, 6(2), 87-97.

Gavirneni, S., \& Isen, A. M. (2010). Anatomy of a newsvendor decision: Observations from a verbal protocol analysis. Production and Operations Management, 19(4), 453-462.

Gino F., \& Pisano, G. (2008). Toward a theory of behavioral operations. Manufacturing and Service Operations Management, 10(4), 676-691.

Hanssens D., Parsons, L., \& Schultz, R. (2001). Market response models, econometric and times series analysis. Norwell, MA: Kluwer Academic Publishers. 
Healy, P. (2014). Ticket pricing puts Lion King atop Broadway's circle of life, accessed October 6, 2014, available at http://www.nytimes. com/2014/03/17/theater/ticket-pricing-puts-lion-king-atop-broadwayscircle-of-life.html.

Ho T. H., \& Zhang, J. (2008). Designing pricing contracts for boundedly rational customers: Does the framing of the fixed fee matter?. Management Science, 54(4), 686-700.

Kalkanci, B., Chen, K., \& Erhun, F. (2011). Contract complexity and performance under asymmetric demand information: An experimental evaluation. Management Science, 57(4), 689-704.

Katok, E., \& Wu, D. Y. (2009). Contracting in supply chains: A laboratory investigation. Management Science, 55(12), 1953-1968.

Kazaz, B., \& Webster, S. (2011). The impact of yield dependent trading costs on pricing and production planning under supply uncertainty. Manufacturing and Service Operations Management, 13(3), 404-417.

Kimes, S. E., (1999). Implementing Restaurant Revenue Management. Cornell Hotel and Restaurant Administration Quarterly (June), 16-21.

Kimes, S. E., Barrash, D. I., \& Alexander, J. E. (1999) Developing a Restaurant Revenue-management Strategy. Cornell Hotel and Restaurant Administration Quarterly (October), 18-29.

Kremer M., Minner, S., \& VanWassenhove, L. N. (2010). Do random errors explain newsvendor behavior?, Manufacturing and Service Operations Management, 12(4), 673-681.

Kocabıyıkoğlu, A., \& Popescu, I. (2011). An elasticity approach to the newsvendor with price-sensitive demand. Operations Research, 59(2), 301-312.

Kolisch, R., \& Zatta, D. (2010). Implementation of revenue management in the process industry of North America and Europe, SKP and T.U.Munchen Working Paper.

Kocabıyıkoğlu, A., Popescu, I., \& Stefanescu, C. (2013). Pricing and revenue management: The value of coordination. Management Science, forthcoming.

Lim, N., \& Ho, T. (2007). Designing price contracts for boundedly rational customers: Does the number of blocks matter? Marketing Science, 26(3), 312326.

Loch, C. H., \& Wu, Y. (2008). Behavioral operations management. Boston MA: New Publishers.

Lurie, N.H., \& Swaminathan, J.M. (2009). Is timely information always better? The effect of feedback frequency on decision making. Organizational Behavior and Human Decision Processes, 108(2), 315-329.

Merrick, A. (2001). Retailers attempt to get a leg up on markdowns with new software, Accesses October 6, 2014, available at http://online. wsj.com/articles/SB997129731937029295 
Moritz, B., Hill, A.V., \& Donohue, K. (2013). Individual differences in the newsvendor problem: Behavior and cognitive reflection. Journal of Operations Management, 31, 72-85.

Petruzzi, N., \& Dada, M. (1999). Pricing and the newsvendor problem: A review with extension. Operations Research, 47(2), 183-194.

Phillips, R.L. (2005). Pricing and revenue optimization. Stanford, CA: Stanford Business Books.

Porteus, E.L. (2002). Foundations of stochastic inventory theory. Stanford, CA: Stanford University Press.

Raz, G., \& Porteus, E.L. (2006). A fractiles perspective to the joint price/quantity newsvendor model. Management Science, 52(11), 1764-1777.

Ren, Y. \& Croson, R. (2013). Overconfidence in newsvendor orders: An experimental study, Management Science, 59(11), 2502-2517.

Schultz K. L., McClain, J. O., Robinson, L.W., \& Thomas, J. (2007). The use of framing in inventory decisions. Working Paper, Cornell University, Ithaca NY.

Schweitzer, M. E., \& Cachon, G. P. (2000). Decision bias in the newsvendor problem with a known demand distribution: Experimental evidence. Management Science, 49(3), 404-420.

Siegel, S. (1956). Nonparametric statistics for behavioral sciences. New York: McGraw-Hill.

Varian, H. (2005). The dynamics of pricing tickets for Broadway shows, accessed October 6, 2014, available at http://www.nytimes. com/2005/01/13/business/13scene.html?_r=0.

Wang, C.X., \& Webster, S. (2009). The loss averse newsvendor problem. Omega, 37(1), 93-105.

Wu, D.Y., \& Chen, K. (2014). Supply chain contract design: Impact of rationality and individual heterogeneity. Productions and Operations Management, 23(2), 253-268.

Wu, C., Petruzzi, N. C., \& Chhajed, D. (2007). Vertical integration with pricesetting competitive newsvendors. Decision Sciences, 38(4), 581-610. 


\section{APPENDIX}

Figure A1: Histogram of subjects' quantity decisions: $Q$ high-margin treatment.

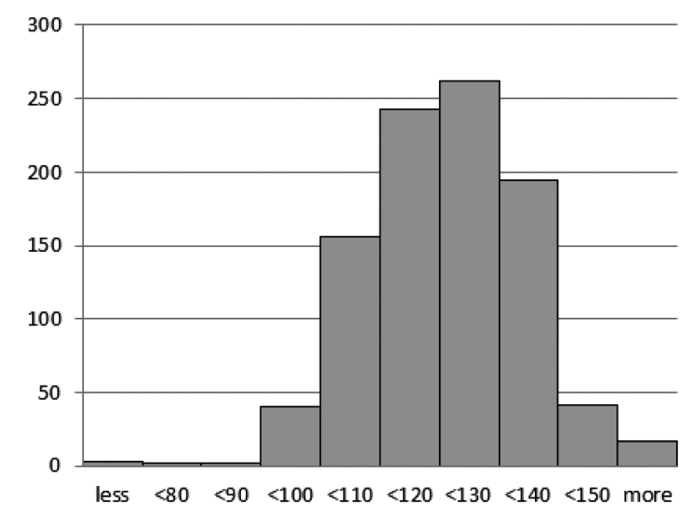

Figure A2: Histogram of subjects' quantity decisions: $Q$ low-margin treatment.

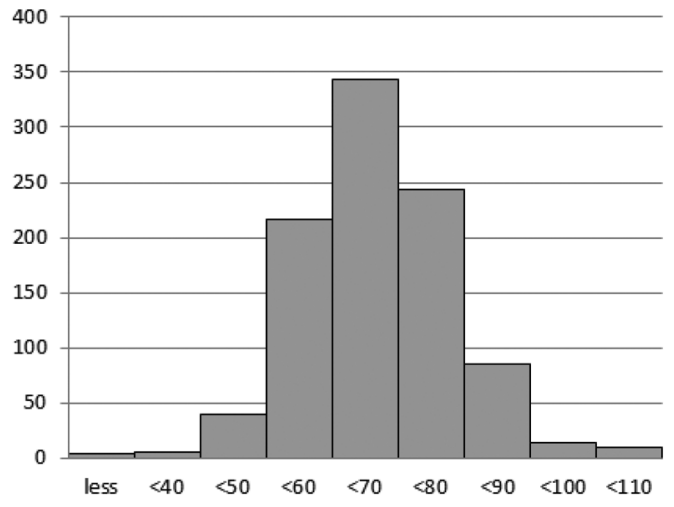


Figure A3: Histogram of subjects' price decisions: $P$ high-margin treatment.

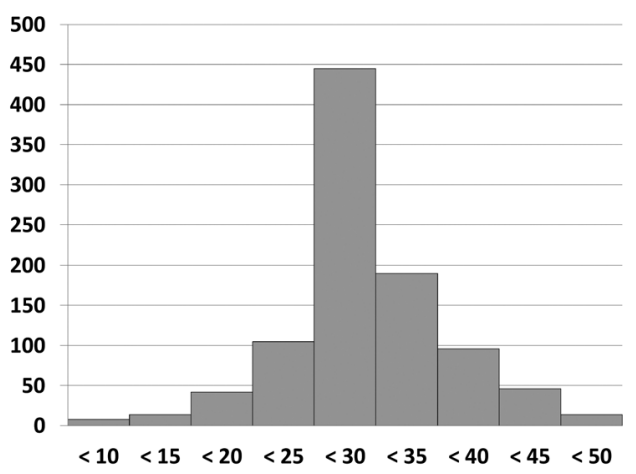

Figure A4: Histogram of subjects' price decisions: $P$ low-margin treatment.

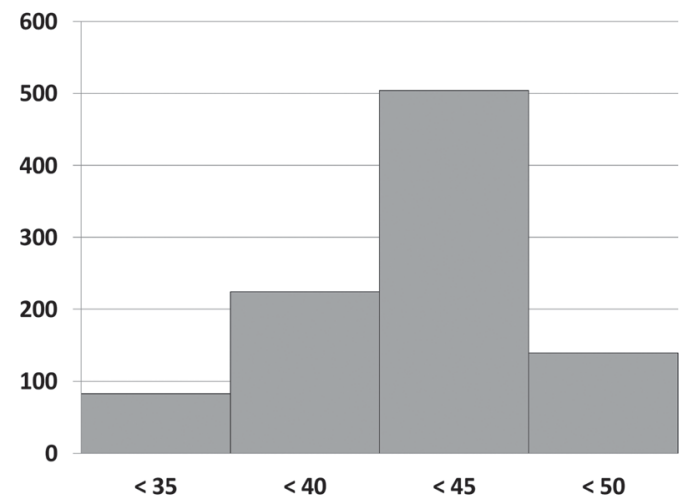

Figure A5: Histogram of subjects' quantity decisions: $P Q$ high-margin treatment.

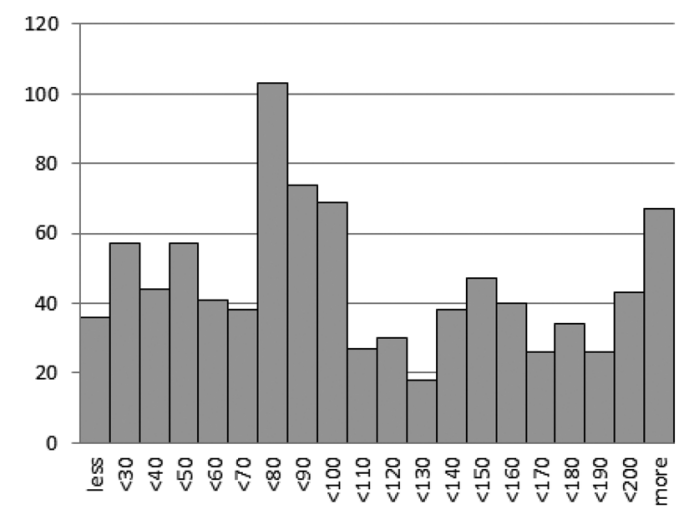


Figure A6: Histogram of subjects' quantity decisions: $P Q$ low-margin treatment.

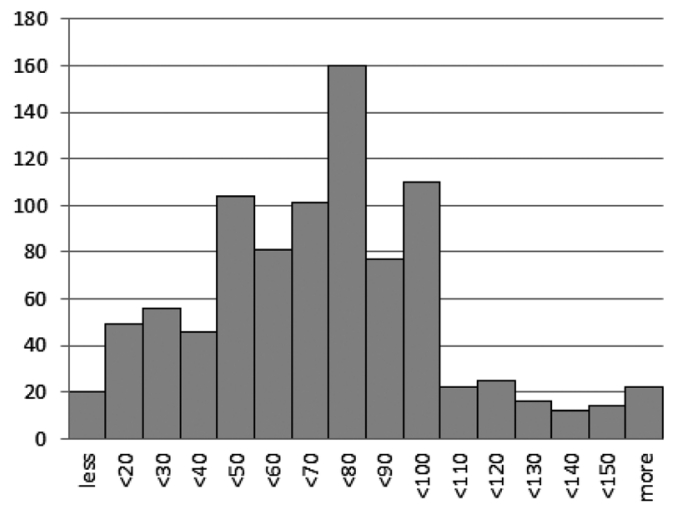

Figure A7: Histogram of subjects' price decisions: $P Q$ high-margin treatment.

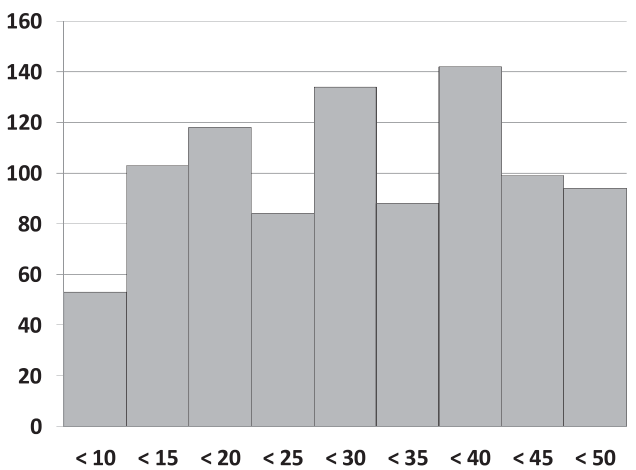

Figure A8: Histogram of subjects' price decisions: $P Q$ low-margin treatment.

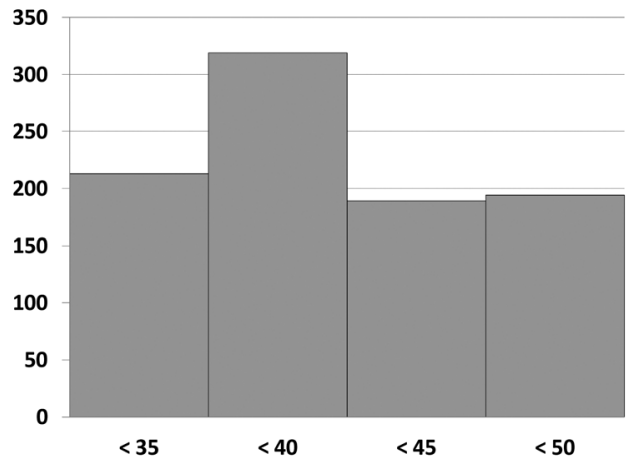


Figure A9: Histogram of mean demands corresponding to subjects' price decisions: $P$ high-margin treatment.

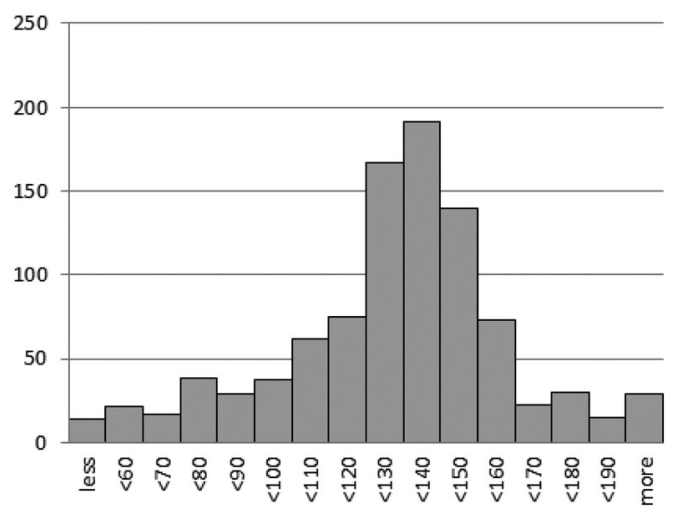

Figure A10: Histogram of mean demands corresponding to subjects' price decisions: $P$ low-margin treatment.

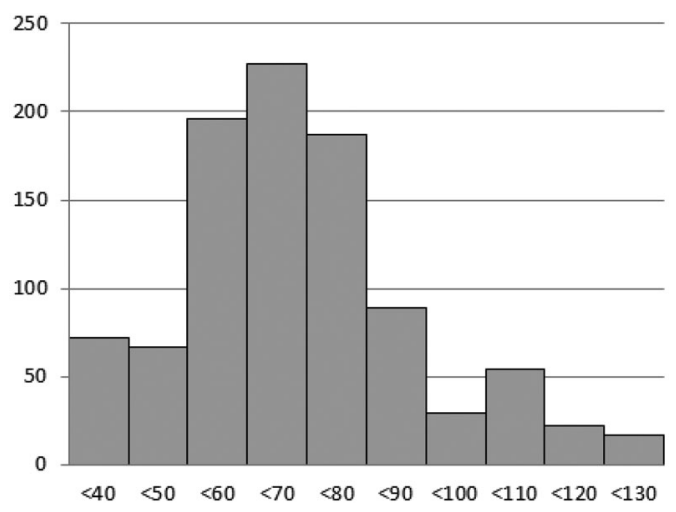


Figure A11: Histogram of the difference between subjects' quantity decisions and mean demands corresponding to their price decision: $P Q$ high-margin treatment.

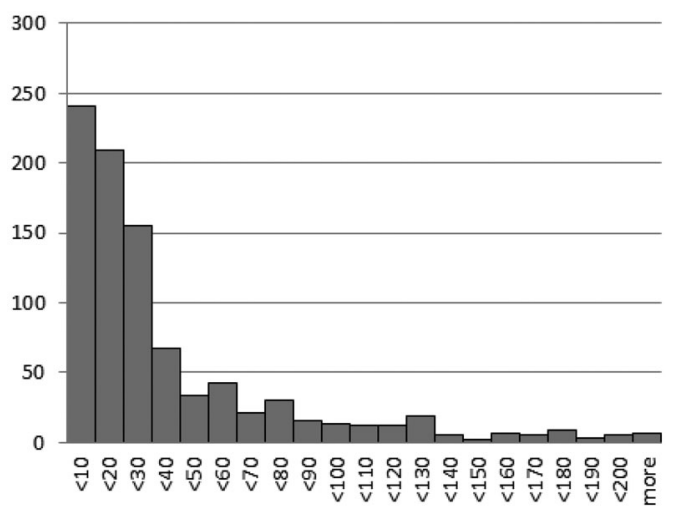

Figure A12: Histogram of the difference between subjects' quantity decisions and mean demands corresponding to their price decision: $P Q$ low-margin treatment.

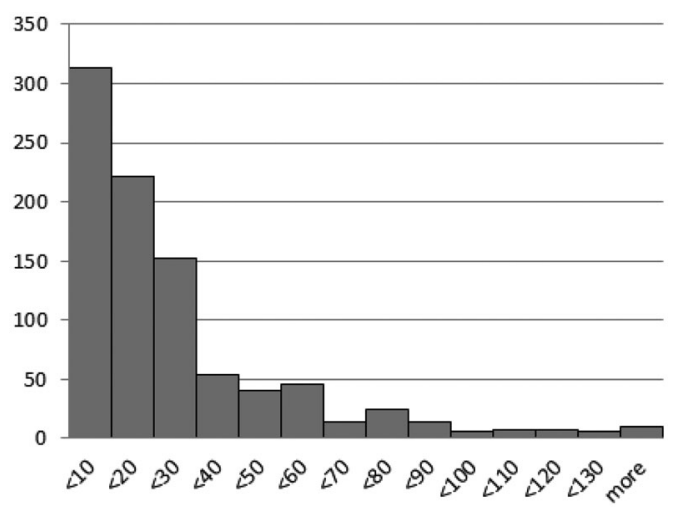


Figure A13: Interface for condition $Q$ high-margin treatment.

\section{Before the decision}

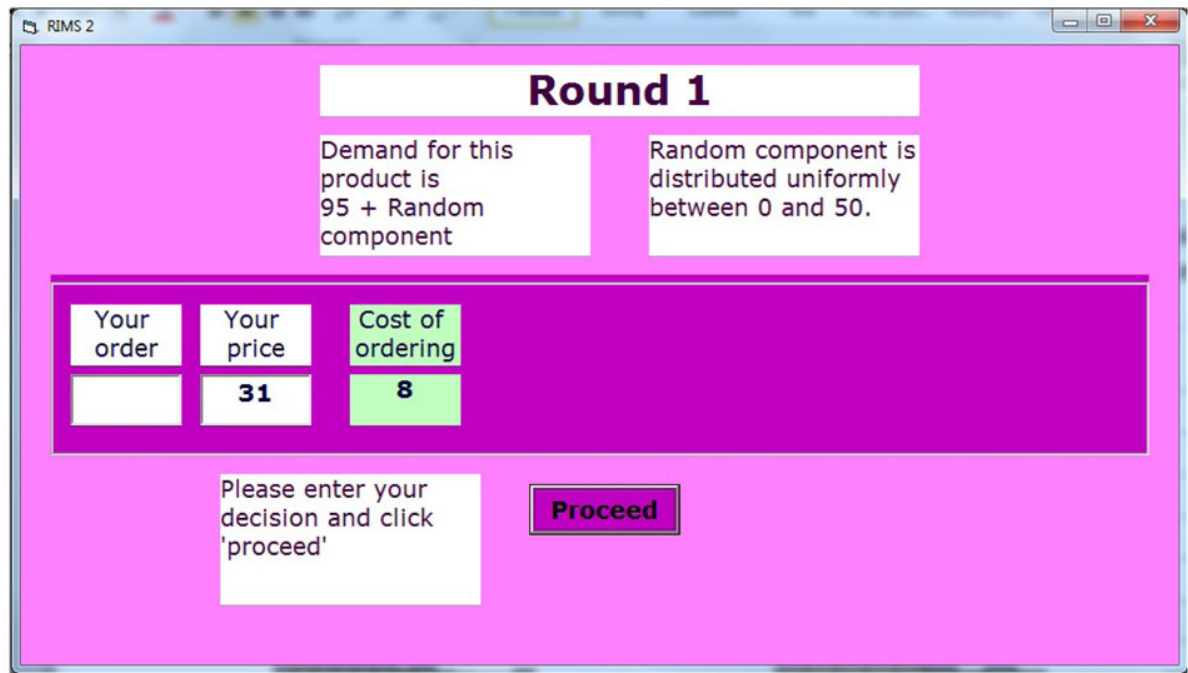

After the decision

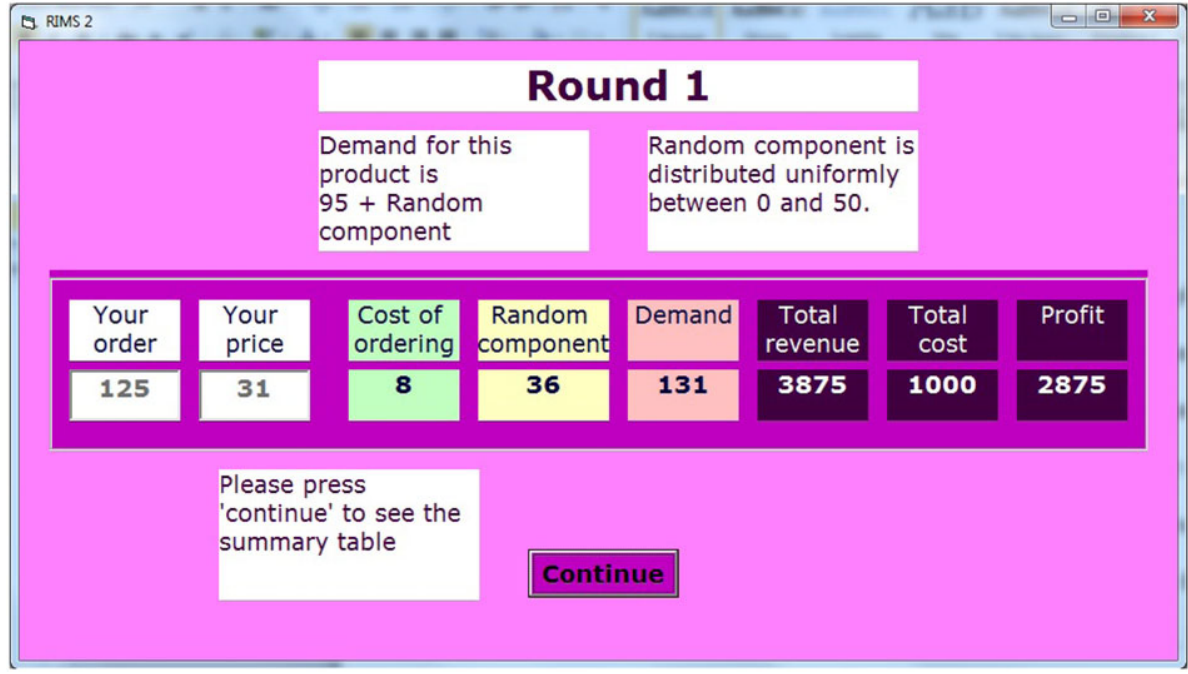


Table A1: Additional descriptive statistics: quantity decisions.

\begin{tabular}{lrrrrrrr}
\hline & \multicolumn{3}{c}{ Subjects' responses } & & \multicolumn{2}{c}{ Subjects' average responses } \\
\cline { 2 - 3 } \cline { 7 - 8 } & Median & Min & Max & & Median & Min & Max \\
\hline High margin & & & & & & \\
$Q$ & 124 & 30 & 290 & & 121.5 & 106.83 & 186.93 \\
$P Q$ & 95 & 1 & 300 & & 90.87 & 27.67 & 206.33 \\
Low margin & 68 & 15 & 120 & & 69.1 & 54.87 & 83 \\
$Q$ & 71 & 0 & 300 & & 72.2 & 11.73 & 163.67 \\
$P Q$ & 71 & & & & & & \\
\hline
\end{tabular}

Table A2: Additional descriptive statistics: price decisions.

\begin{tabular}{lccccccc}
\hline & \multicolumn{3}{c}{ Subjects' responses } & & \multicolumn{2}{c}{ Subjects' average responses } \\
\cline { 2 - 3 } & Median & Min & Max & & Median & Min & Max \\
\hline High margin & & & & & & & \\
$P$ & 29 & 8 & 50 & & 29.7 & 17.87 & 42.2 \\
$P Q$ & 30 & 8 & 50 & & 30 & 11 & 50 \\
Low margin & & & & & & & \\
$P$ & 42 & 30 & 50 & & 42.03 & 36.27 & 46.4 \\
$P Q$ & 40 & 30 & 50 & & 40.33 & 32.67 & 48.67 \\
\hline
\end{tabular}

Table A3: Profit analysis: high-margin treatment.

\begin{tabular}{lllccc}
\hline & $\begin{array}{c}\text { Profits } \\
\text { under } Q\end{array}$ & $\begin{array}{c}\text { Profits } \\
\text { under } P\end{array}$ & $\begin{array}{c}\text { Profits under } \\
P Q \text { with } p=p^{*}\end{array}$ & $\begin{array}{c}\text { Profits under } \\
P Q \text { with } q=q^{*}\end{array}$ & $\begin{array}{c}\text { Profits } \\
\text { under } P Q\end{array}$ \\
\hline Average & 2450.91 & 2174.91 & 1665.47 & 1481.83 & 1451.72 \\
Median & 2464.67 & 2282.07 & 1899.8 & 1501.67 & 1432.6 \\
Min & 2044.73 & 1243.73 & 627.13 & -26 & 344.2 \\
Max & 2536.4 & 2512 & 2399.6 & 2512 & 2398.2 \\
\hline
\end{tabular}

Note: The normative average profit (when $p=p^{*}$ and $q=q^{*}$ ) is 2513 under this treatment. 
Table A4: Profit analysis: low-margin treatment.

\begin{tabular}{lccccr}
\hline & $\begin{array}{c}\text { Profits } \\
\text { under } Q\end{array}$ & $\begin{array}{c}\text { Profits } \\
\text { under } P\end{array}$ & $\begin{array}{c}\text { Profits under } \\
P Q \text { with } p=p^{*}\end{array}$ & $\begin{array}{c}\text { Profits under } \\
P Q \text { with } q=q^{*}\end{array}$ & $\begin{array}{c}\text { Profits } \\
\text { under } P Q\end{array}$ \\
\hline Average & 564.02 & 453.58 & 227.73 & 306.33 & 152.23 \\
Median & 573 & 455.73 & 342.47 & 311.67 & 303.33 \\
Min & 349.4 & 201.8 & -1878.73 & -242 & -1726.33 \\
Max & 683.47 & 630.73 & 601.2 & 614.47 & 596.67 \\
\hline
\end{tabular}

Note: The normative average profit (when $p=p^{*}$ and $q=q^{*}$ ) is 602 under this treatment.

Ayşe Kocabıyıkoğlu is an Assistant Professor of Decision Sciences at Bilkent University in Ankara, Turkey, and holds a PhD in Decision Sciences from INSEAD, and MS and BS degrees from Middle East Technical University. Her research is at the interface of decision sciences and behavioral operations, and her research interests include behavioral operations management, pricing and revenue management, and dynamic decision making. Her work has featured in leading academic journals such as Management Science, Operations Research and Production \& Operations Management.

Celile Itır Göğüs is an Assistant Professor of Management at Bilkent University in Ankara, Turkey. She has completed her PhD in Management and MS in Human Resource Management at Mays Business School, Texas A\&M University and BS in Management at Bilkent University. Her research interests include behavioral applications of organizational phenomena including managerial behavior and decision making. Her research has appeared in journals such as the Production \& Operations Management, Journal of Applied Psychology, Journal of Business Ethics, Small Group Research, Applied Psychology and also as book chapters.

M. Sinan Gönül is an Associate Professor of Decision Sciences in the Department of Business Administration at Middle East Technical University (METU) in Ankara, Turkey. He has carried out research in the areas of judgmental forecasting, judgment \& decision making and behavioral operations research. He has published in various journals including Journal of Behavioral Decision Making, Decision Sciences Journal, Decision Support Systems, International Journal of Forecasting, Journal of Forecasting, Technological Forecasting \& Social Change and Production and Operations Management. 